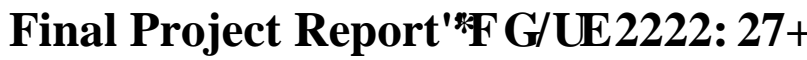

\author{
$12 / 2008$ to $4 / 2013$ \\ Principal Investigator: Guang Zhang
}

Division of Climate, Atmospheric Science and Physical Oceanography

Scripps Institution of Oceanography

La Jolla, CA 92093-0221

Tel: 858-534-7535

Email: gzhang@ucsd.edu

\section{Title of Research Grant: Improving Convection Parameterization Using ARM Observations and NCAR Community Atmosphere Model}

\section{Highlight of Accomplishments:}

We made significant contribution to the ASR program in this funding cycle by better representing convective processes in GCMs based on knowledge gained from analysis of ARM/ASR observations. In addition, our work led to a much improved understanding of the interaction among aerosol, convection, clouds and climate in GCMs. Below is a highlight of our achievements.

- We examined the role of entrainment in convection parameterization using the ARM data.

We investigated the effect of entrainment dilution on CAPE and closure assumptions in convection parameterization using the sounding data from three Intensive Observation Periods of ARM. It was shown that entrainment of the environmental air has a strong dilution effect on CAPE, and this effect depends on the degree of subsaturation of the entrained air: the drier the entrained air, the larger the effect. For CAPE-based closure assumption, the dilute CAPE has a moderate correlation with convective removal of CAPE. While better than for undiluted CAPE, which is virtually uncorrelated with convective CAPE removal, this correlation is not satisfactory enough for convection closure. For quasi-equilibrium-based closures, while the free tropospheric quasi-equilibrium assumption is a superior closure for convection when undiluted CAPE is used, both the Arakawa-Schubert quasi-equilibrium closure and the free tropospheric quasiequilibrium closure work well for dilute CAPE in all three IOPs studied. It was further shown from the CAPE definition and the large-scale temperature budget equation that for undiluted CAPE the free tropospheric large-scale CAPE change and precipitation are linearly related. This provides a physical basis for the free tropospheric quasi-equilibrium closure assumption. The most important effect of entrainment dilution on CAPE and convection parameterization closure assumptions is to diminish the overwhelming role of boundary layer control on CAPE and its variation.

- We identified the interaction between deep and shallow convection as a key factor for simulation of Madden Julian Oscillation

This research investigated the role of the interaction between deep and shallow convection in MJO simulation using the NCAR CAM3. Two simulations were performed, one using a revised Zhang-McFarlane convection scheme for deep convection and the Hack scheme 
for shallow convection, and the other disabling shallow convection below $700 \mathrm{mb}$ in the tropical belt. The two simulations produce dramatically different MJO characteristics. While the control simulation produced realistic MJOs, the simulation without shallow convection had very weak MJO signals in the Indian Ocean and western Pacific. We performed composite analysis and found that shallow convection served to precondition the lower troposphere by moistening it ahead of deep convection. It also produced enhanced low-level mass convergence below $850 \mathrm{mb}$ ahead of deep convection. This work demonstrated that a correct simulation of the interaction between deep and shallow convection was key to MJO simulation in global climate models.

- We investigated the aerosol direct effect on Asian summer monsoon simulation

In this work, we investigated the effects of aerosols on the simulation of the Indian monsoon by the NCAR Community Atmosphere Model. Monthly-mean 3D mass concentrations of soil dust, black and organic carbons, sulfate, and sea salt, as output from the GOCART model, are used. With these aerosol concentrations, CAM3 is run for a period of 16 months, allowing for one complete episode of the Indian monsoon. Responses to the aerosols are measured by comparing the mean of an ensemble of aerosol-induced monsoon simulations to the mean of an ensemble of CAM3 simulations in which aerosols are omitted. Additionally, an ensemble of simulations of CAM3 using climatological mid-month aerosol concentrations from the NCAR MATCH model is composed for comparison. Results of this experiment indicate that the inclusion of aerosols results in large responses in surface temperature and precipitation over central India during the pre-monsoon and monsoon months. The presence of aerosols induces tropospheric shortwave heating over central India, which destabilizes the atmosphere for enhanced convection and precipitation. Reduced shortwave heating and enhanced evaporation at the surface results in reduced terrestrial emission to cool the lower troposphere, relative to simulations with no aerosols. This effect weakens the near-surface cyclonic circulation and, consequently, has a negative feedback on the monsoon simulation, ending it prematurely.

- We gained a better understanding of the double ITCZ syndrome in the NCAR coupled oceanatmosphere model CCSM3

We investigated the coupled atmosphere-ocean feedback and the role of ocean dynamic heat transport in the formation of double ITCZ over the tropical Pacific in the NCAR Community Climate System Model, version 3 (CCSM3) and its alleviation when a revised Zhang-McFarlane (ZM) convection scheme is used. A hierarchy of coupling strategy was employed for this purpose. A slab ocean model was coupled with the atmospheric component of the Community Atmosphere Model, version 3 (CAM3) to investigate the local feedback between the atmosphere and the ocean. It was shown that the net surface energy flux differences in the southern ITCZ region between the revised and original ZM scheme seen in the stand-alone CAM3 simulations can cool the SST by up to $1.6 \mathrm{C}$. However, the simulated SST distribution was very sensitive to the prescribed ocean heat transport required in the slab ocean model. To understand the role of ocean heat transport, the fully coupled CCSM3 model was used. Through the analysis of CCSM3 simulations, we found that the altered ocean dynamic heat transport when the revised ZM scheme is used was largely responsible for the reduction of SST bias in the southern ITCZ region, although surface energy flux also helped to cool the SST in the first few months of the year in seasonal variation. The results suggest that the unrealistic simulation of convection over the southern ITCZ region in the standard CCSM3 leads to the double-ITCZ bias through complex coupled interactions between atmospheric convection, surface winds, latent heat flux, cloud 
radiative forcing, SST, and upper-ocean circulations. The mitigation of the double-ITCZ bias using the revised ZM scheme is achieved by altering this chain of interactions.

- We developed a physically-based two-moment microphysics scheme for convection for CAM5

To improve the interaction between aerosols, convection and climate in GCMs, we developed a two-moment microphysics parameterization scheme for convective clouds. The scheme explicitly treats mass mixing ratio and number concentration of four hydrometeor species (cloud water, cloud ice, rain and snow), and describes several microphysical processes, including autoconversion, self-collection, collection between hydrometeor species, freezing, cloud ice nucleation, droplet activation, and sedimentation. Thus this physically-based scheme is suitable for investigating the interaction between convection and aerosol, and the indirect aerosol effect on climate. An evaluation of the scheme in the single-column version of NCAR Community Atmospheric Model version 3.5 (CAM3.5) with the Tropical Warm Pool - International Cloud Experiment (TWP-ICE) data shows that the simulation of cloud microphysical properties in convective core is significantly improved. The contribution from convective detrainment to large-scale cloud ice and liquid water budgets is enhanced greatly. With more realistic convective cloud microphysical properties and their detrainment, the surface stratiform precipitation, which is seriously underestimated in the model, is increased by a factor of roughly 2.5, and therefore is much closer to the observations. In addition, the simulations of net surface shortwave radiation flux, OLR, specific humidity, and temperature are also improved. We implemented the scheme into the NCAR CAM5. Results show that it produces cloud properties in convective updrafts agreeing well with satellite observations. The scheme has significant effects on CAM5 simulation of precipitation and radiation budget.

- We gained better understanding on the role of shallow convection in MJO simulation through heat and moisture budget analysis

The role of shallow convection in MJO simulation is examined in terms of the moist static energy (MSE) and moisture budgets. Two simulations are carried out using the NCAR CAM3.0 model: a control run and an experiment that is the same as the control run except with shallow convection disabled below $700 \mathrm{hPa}$ between $20^{\circ} \mathrm{S}-20^{\circ} \mathrm{N}$. While the control run gives a better simulation of the MJO lifecycle when compared with the reanalysis data, the experiment run shows substantially weaker MJO signal. Both the reanalysis data and simulations show recharge-discharge mechanism in the MSE evolution which is dominated by the moisture anomalies. However, in the experiment run the development of MSE and moisture anomalies is weaker and confined to a shallow layer at the developing phases, which may prevent further development of deep convection. By conducting the budget analysis on both the MSE and moisture, it is found that the major biases in the experiment run is largely attributed to the vertical and horizontal advection. Without shallow convection, the lack of gradual deepening of upward motion during the developing stage of MJO prevents the lower troposphere above the boundary layer from being preconditioned for deep convection.

In addition to our model improvement work and understanding of tropical climate systems, we also made the following accomplishments:

- The project resulted in fourteen peer-reviewed journal papers and numerous conference presentations. 
- We continued our close collaboration with the CAPT team at LLNL.

- We have actively participated in the ASR Science Team meetings and Cloud Life Cycle Working Group activities.

\section{Postdoctoral fellows and students trained:}

Qiongqiong Cai, Craig Collier, Aditya Murthy, Suhas Ettammal, Xiaoliang Song

\section{Journal publications resulting from ASR support:}

1. Song, X., and G. J. Zhang, 2009: Convection parameterization, tropical Pacific double ITCZ, and upper ocean biases in the NCAR CCSM3. Part I: Climatology and atmospheric feedback. J. Climate, 22, 4299-4315.

2. Zhang, G. J., and X. Song, 2009: Interaction of deep and shallow convection is key to Madden-Julian Oscillation simulation, Geophys. Res. Lett., 36, L09708, doi:10.1029/2009GL037340.

3. Zhang, G. J., 2009: Effects of entrainment on convective available potential energy and closure assumptions in convection parameterization. J. Geophys. Res., 114, D07109, doi:10.1029/2008JD010976.

4. Collier, J. C., and G. J. Zhang, 2009: Aerosol direct forcing of the summer Indian monsoon as simulated by the NCAR CAM3. Clim. Dyn., 32, 313-332, DOI 10.1007/s00382-008-04649.

5. Park, H., J. Chiang, B. Lintner, and G. J. Zhang, 2010: The delayed effect of major El Nino events on Indian monsoon rainfall. J. Climate, 23, 932-946.

6. Song, X., D. Lubin, and G. J. Zhang, 2010: Increased greenhouse gases enhance regional climate response to a Maunder Minimum, Geophys. Res. Lett., 37, L01703, doi:10.1029/2009GL041290.

7. Zhang, G. J., and X. Song, 2010: Convection parameterization, tropical Pacific double ITCZ, and upper ocean biases in the NCAR CCSM3. Part II: Coupled feedback and the role of ocean heat transport. J. Climate, 23, 800-812.

8. Zhang, G. J., A. M. Vogelmann, M. P. Jensen, W. D. Collins, and E. Luke, 2010: Relating satellite observed cloud properties from MODIS to meteorological conditions for marine boundary layer clouds. J. Climate, 23, 1374-1391.

9. Chen, H., T. Zhou, R. B. Neale, X. Wu, and G. J. Zhang, 2010: Performance of the new NCAR CAM3.5 model in East Asian summer monsoon simulation: Sensitivity to modifications to convection scheme. J. Climate, 23, 3657-3675.

10. Song, X., and G. J. Zhang, 2011: Microphysics parameterization for convective clouds in a global climate model: Description and single-column model tests. J. Geophys. Res., 116, D02201, doi:10.1029/2010JD014833.

11. Jiang, X., D. E. Waliser, D. Kim, M. Zhao, K. R. Sperber, W. Stern, S. D. Schubert, G. J. Zhang, W. Wang, M. Khairoutdinov, R. Neale, and M.-I. Lee, 2011: Simulation of the intraseasonal variability over the eastern Pacific ITCZ in climate models. Clim. Dyn., DOI 10.1007/s00382-011-1098-X.

12. Song, X., G. J. Zhang, and J.-L. F. Li, 2012: Evaluation of microphysics parameterization for convective clouds in the NCAR Community Atmosphere Model CAM5. J. Climate, 25, 8568-8590, DOI: 10.1175/JCLI-D-11-00563.1 
13. Cai, Q., G. J. Zhang, and T. Zhou, 2013: Impacts of shallow convection on MJO simulation: A moist static energy and moisture budget analysis. J. Climate, 26, 2417-2431.

14. Zhang, G.J., M. Cai, and A. Hu, 2013: Energy consumption and the unexplained winter warming over northern Asia and North America. Nature Climate Change, 3, 466-470, DOI:10.1038/NCLIMATE1803.

\section{Conference abstracts and workshop presentations:}

Zhang, G. J., and X. Song, 2009: Interaction of convection and SST in the formation and disappearance of double ITCZs in the NCAR CCSM3. $89^{\text {th }}$ AMS Annual Meeting, Jan. 11-15, Phoenix, AZ.

Zhang, G. J., 2009: Linking Convection Parameterization to Tropical Pacific Double ITCZ and Upper Ocean Biases in the NCAR CCSM3. $19^{\text {th }}$ ARM Science Team Meeting, March 1519, 2009, Louisville, KY.

Zhang, G. J., and X. Song 2009: Effects of Entrainment on Closure Assumptions in Convection Parameterization. AGU Spring Meeting, May 24-27, Toronto, Ontario, Canada.

Zhang, G. J., X. Song, 2009: Coupled feedback and ocean heat transport in the simulation of ITCZ. AGU Fall Meeting, San Francisco, CA, Dec. 14-18, 2009.

Song, X., G. J. Zhang, and D. Lubin, 2009: What is the Sun enters a Maunder Minimum tomorrow? AGU Fall Meeting, San Francisco, CA, Dec. 14-18, 2009.

Collier, J. C., and G. J. Zhang, 2010: A climate model investigation of lower-tropospheric wind speed biases over wind farm development regions of the continental United States. AMS 90th Annual Meeting, Atlanta, GA, January 17-21, 2010.

Zhang, G. J., and X. Song, 2010: Microphysics Parameterization in Convection and its Effects on Cloud Simulation in the NCAR CAM5. AGU Fall Meeting, San Francisco, CA, Dec. 13$17,2010$.

Zhang, G. J., and X. Song, An update on convection microphysics parameterization. ARM Science Team working group meeting, Boulder, CO, Oct. 14-15, 2010.

Song, X., and G. J. Zhang: 2011: A Microphysics Parameterization for Convective Clouds in a Global Climate Model, 91 ${ }^{\text {st }}$ AMS Annual Meeting, Seattle, WA, Jan. 23-28, 2011.

Zhang, G. J., 2011: Convection parameterization and tropical climate simulation. Workshop on Organized Tropical Convection and Large-Scale Circulation: Theory, Modeling, and Observations. Banff, Alberta, Canada, April 30- May 6, 2011.

Zhang, G. J., Q. Cai, T. Zhou, and C. Chung, 2011: Roles of Deep and Shallow Convection in MJO Simulation: Budget Analysis and Comparison between CAM3 and ECHAM5. YOTC International Science Symposium and 8th AMY Workshop. Beijing, China, May 16-19, 2011.

Song, X., G. J. Zhang, and M. Cai, 2011: Understanding the Spatial Patterns of Global Warming and Climate Feedbacks with a New Analysis Approach, AGU Fall Meeting, San Francisco, CA, Dec. 4-9, 2011.

Chen, B. V. Ramanathan, J. Huang, G. J. Zhang and Y. Xu, 2011: Estimating absorbing black carbon and organic carbon optical properties from AERONET and MISR data over East Asia, AGU Fall Meeting, San Francisco, CA, Dec. 4-9, 2011.

Song, X., G. J. Zhang, and F. Li, 2012: Evaluation of Microphysics Parameterization for Convective Clouds in the NCAR Community Atmosphere Model CAM5, AGU Fall Meeting, San Francisco, CA, Dec. 3-7, 2012. 
Alapaty, K., G. J. Zhang,_X. Song, J. S. Kain, and J. A. Herwehe, 2012: Introducing Convective Cloud Microphysics to a Deep Convection Parameterization Facilitating Aerosol Indirect Effects, AGU Fall Meeting, San Francisco, CA, Dec. 3-7, 2012.

Zhang, G.J., and X. Song, 2013: Convective microphysics and its interaction with aerosols and climate in a global climate model. American Mathematical Society Meeting, Special Session on Environmental Mathematics, San Diego, CA, January 9-12, 2013. 